OPEN ACCESS

Edited by:

Ravi Misra,

University of Rochester, United States

Reviewed by:

Rasheed Gbadegesin,

Duke University, United States

Qiu Li,

Chongqing Medical University, China

*Correspondence:

Manuela Colucci

manuela.colucci@opbg.net

Specialty section:

This article was submitted to Autoimmune and Autoinflammatory

Disorders,

a section of the journal

Frontiers in Immunology

Received: 26 November 2021

Accepted: 04 January 2022

Published: 24 January 2022

Citation:

Colucci M, Oniszczuk J, Vivarelli M and Audard V (2022) B-Cell Dysregulation

in Idiopathic Nephrotic Syndrome:

What We Know and What

We Need to Discover.

Front. Immunol. 13:823204.

doi: 10.3389/fimmu.2022.823204

\section{B-Cell Dysregulation in Idiopathic Nephrotic Syndrome: What We Know and What We Need to Discover}

\author{
Manuela Colucci $^{{ }^{*}}$, Julie Oniszczuk ${ }^{2,3}$, Marina Vivarelli $^{4}$ and Vincent Audard ${ }^{2,3}$ \\ 1 Renal Diseases Research Unit, Genetics and Rare Diseases Research Area, Bambino Gesù Children's Hospital, Istituto di \\ Ricovero e Cura a Carattere Scientifico (IRCCS), Rome, Italy, ${ }^{2}$ Assistance Publique des Hôpitaux de Paris, Hôpitaux \\ Universitaires Henri-Mondor, Service de Néphrologie et Transplantation, Centre de Référence Maladie Rare "Syndrome \\ Néphrotique Idiopathique", Fédération Hospitalo-Universitaire, Innovative Therapy for Immune Disorders, Créteil, France, \\ 3 Univ Paris Est Créteil, Institut National de la Santé et de la Recherche Médicale (INSERM) U955, Institut Mondor de \\ Recherche Biomédicale (IMRB), Créteil, France, ${ }^{4}$ Division of Nephrology, Department of Pediatric Subspecialties, Bambino \\ Gesù Children's Hospital, Istituto di Ricovero e Cura a Carattere Scientifico (IRCCS), Rome, Italy
}

The therapeutic efficacy of B-cell depletion by anti-CD20 treatment in pediatric and, more recently, in adult idiopathic nephrotic syndrome patients suggests a key role of B cells in the pathogenesis of the disease. However, their exact role is still unclear. B cells are able to secrete a large variety of antibodies that can protect against infections. However, B-cell dysregulation is well-established in a variety of autoimmune diseases. In parallel with their ability to produce antibodies, pathogenic B cells display altered effector functions by expressing activating surface molecules, which can strongly modify the immune homeostasis, or by producing specific cytokines, which can directly affect either podocyte structure and functions or modulate T-cell homeostasis. Herein, we report the most relevant clinical and experimental evidences of a pathogenic role of $\mathrm{B}$ cells in idiopathic nephrotic syndrome. We further highlight similarities and differences between children and adults affected by non-genetic forms of the disease and discuss what needs to be investigated in order to define the exact mechanisms underlying the pathogenic role of B cells and to identify more tailored therapeutic approaches.

Keywords: Idiopathic Nephrotic syndrome (INS), minimal change disease (MCD), focal segmental glomerulosclerosis (FSGS), B cells, antibodies, cytokines

\section{INTRODUCTION}

Idiopathic nephrotic syndrome (INS), which includes two main histological entities, minimal change disease (MCD) and primary focal segmental glomerulosclerosis (FSGS), is the most frequent glomerular disease in childhood, with an incidence of 1.2-16.9/100,000 children (1). It is characterized by an intense proteinuria associated with hypoalbuminemia and edema due to an alteration of the glomerular permeability barrier leading to podocyte foot-process effacement (1). The response to a standardized steroid-treatment is more predictive of the disease course than histological findings in children, and kidney biopsy is usually not performed in steroid-sensitive INS (SSNS) pediatric patients (1). However, when biopsy is performed, most children present MCD (2). 
In contrast, kidney biopsy, which is routinely performed at onset of nephrotic syndrome in adults, shows a very low incidence of INS (0.6-1.8 per 100,000 adults), with the majority of patients presenting other glomerular diseases, mainly membranous nephropathy (2). In adult patients, MCD is less frequent than FSGS (3). Similarly to children, steroid treatment is the first-line therapeutic approach also for adults. However, a more prolonged treatment is necessary to induce remission compared to pediatric forms $(2,4)$. The pathogenesis of INS is still not well elucidated, but the therapeutic approaches based on immunosuppressive agents largely support a key role of the immune system in steroid-sensitive forms of the disease (5). In these forms, the disruption of the glomerular barrier leading to podocyte cytoskeleton disorganization and subsequent proteinuria seems to be mediated by one or more circulating factors, derived from dysregulated immune cells (6). Nonetheless, until now, the identity of this (these) factor(s) remain(s) undetermined $(5,6)$. Moreover, both in MCD and in FSGS the renal biopsy shows little or no evidence of glomerular inflammation and of immunoglobulin or complement deposition. For more than 30 years, INS was considered as a T-cell mediated disease (7), and several preclinical and clinical studies largely supported this hypothesis (5). More recently, a potential role of B cells has emerged due to the therapeutic efficacy of the B-cell depleting anti-CD20 antibodies (rituximab and ofatumumab) in inducing and/or maintaining a prolonged remission in children with INS (8-11). Similar results from non-prospective randomized clinical trials suggest that B-cells depleting agents may be useful in adult patients with steroid dependent or frequently relapsing INS to reduce the relapse frequency and to maintain remission despite cessation or tapering of steroids and/or immunosuppressive drugs (3). In addition, previous findings show that INS may occur in association with non-Hodgkin lymphoproliferative disorders or Hodgkin lymphoma where tumor cells derive from mature B cells (12-14) and with Epstein Barr virus infection, which mainly targets B cells (15). Altogether, these findings provide additional evidence implicating B lymphocytes as a key immune cell type involved in INS pathogenesis.

In this review, we describe phenotype and function of B cells and report the most relevant clinical and experimental indications of their potential role in the pathogenesis of INS. Current knowledge regarding potential effects exerted by $\mathrm{B}$ lymphocytes in INS pathogenesis is summarized in Figure $\mathbf{1}$.

\section{B-CELL PHENOTYPE AND FUNCTION}

B cells are a heterogeneous population composed by different subsets and the physiological distribution of these subpopulations is age-dependent (16). During infancy, the peripheral B-cell pool is predominantly characterized by transitional B cells, which migrate from the bone marrow to the periphery where they acquire a naïve/mature phenotype. Through the circulation into secondary lymphoid organs, they encounter antigens that can induce their activation and differentiation into plasmablasts, which are the precursors of antibody secreting plasma cells, or memory B cells, which can produce IgM or undergo toward an isotype switching to IgG-, IgA-, or IgE-secreting B cells. Circulating plasmablasts and plasma cells generally die after few days, but some long-lived plasma cells return to the bone marrow and maintain antibody production independently of antigen exposure. From infancy to adulthood, the circulating levels of transitional, mature-naïve, memory B cells and plasmablasts/plasma cells progressively decrease, reaching a relatively stable number in adulthood (16).

Beside their ability in producing a large variety of antibodies that can protect from infections - the so called "humoral immunity" - B cells can also modify the homeostasis of specific tissues by producing immunoregulatory or pro-inflammatory cytokines and by expressing surface molecules able to present antigens which can in turn activate circulating $\mathrm{T}$ cells $(17,18)$. In particular, regulatory $\mathrm{B}$ cells produce immunomodulatory cytokines such as IL-10 and IL-35, which can dampen immune responses in pathological and transplant settings $(18,19)$. In parallel, B cells are able to directly or indirectly promote the activation of effector $\mathrm{T}$ cells by secreting pro-inflammatory cytokines such as IFN-gamma, TNF-alpha, IL-6 and IL-17 (20). During activation, B cells also express molecules such as HLA class II, CD40, CD80 and CD86, which stabilize the interactions between $\mathrm{B}$ and $\mathrm{T}$ cells and can sustain $\mathrm{T}$-cell activation in autoimmune and auto-inflammatory diseases (17, $18,21)$.

\section{PATHOGENIC ANTIBODIES IN INS}

In contrast to the vast majority of the glomerular diseases, INS is usually not considered an antibody-mediated disease due to the lack of immunoglobulin deposits in kidney biopsies (22). Of note, glomerular IgM deposition, which can be observed in some forms of FSGS, seems to derive from a binding of IgM (together with activated complement factors) to epitopes that are exposed after injury of glomerular cells, suggesting that IgM may contribute to disease progression more than representing the causative factor $(23,24)$. However, a pathogenic role of circulating antibodies in INS has been hypothesized since 1998, when Dantal et al. showed that a permeability factor inducing albuminuria could be or could be bind to an immunoglobulin (25). In addition, an imbalance between serum IgG and serum IgM that sometimes persists during remission of the disease has been reported, suggesting a dysregulated immunoglobulin metabolism in INS $(26,27)$. More recently, potentially pathogenic IgG directed against surface podocyte proteins have been described in adult and pediatric INS (28-30). In particular, increased serum levels of anti-CD40 IgG were observed in adults with recurrent FSGS. These antibodies were able to cause a disruption of actin cytoskeleton of in vitro cultured podocytes and to induce proteinuria (in the presence of recombinant soluble urokinase plasminogen activator receptor) in injected mice (28). Unfortunately, the presence of glomerular IgG deposition following anti-CD40 injection was not evaluated in this study. In 2018, Jamin et colleagues reported increased serum 


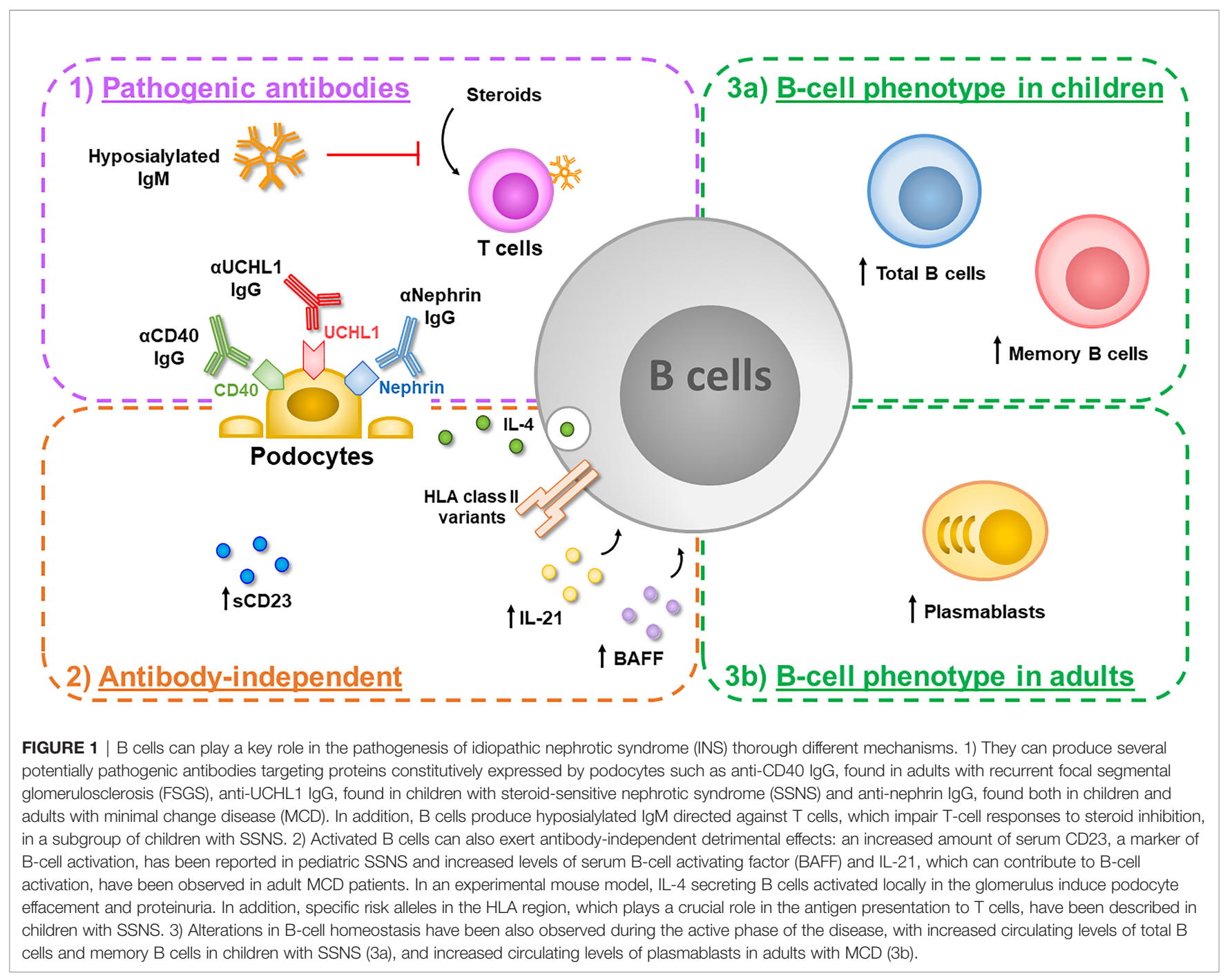

levels of anti-UCHL1 IgG in children with SSNS (29). AntiUCHL1 antibodies were able to cause a detachment of in vitro cultured podocytes and to induce an intense proteinuria when injected into mice (29). Interestingly, a pathological finding of MCD without glomerular IgG deposits was observed in injected mice and authors hypothesized that the binding of anti-UCHL1 IgG to surface UCHL1 could lead to podocyte detachment, explaining the absence of IgG deposits in INS kidney biopsies (29). Additional studies are needed to verify this intriguing hypothesis and to validate the real pathogenic role of the described anti-podocyte IgG. A more recent study showed that autoantibodies targeting nephrin, the major transmembrane protein of the podocyte slit diaphragm that links the interdigitating foot processes from neighboring podocytes, may be found in $29 \%$ of patients (both in children and adults) with biopsy-proven MCD (30). Since IgG deposits in kidney biopsy is an ultra-rare finding in kidney biopsy from patients with INS, the accurate role of these potential pathogenic antibodies remains to be determined. Nevertheless, this finding, highlighting that mechanisms underlying INS pathogenesis may involve autoimmune processes, deeply modifies our knowledge about this glomerular disease. Additional studies investigating the disrupting ability of the identified INS-associated autoantibodies, purified by sera or supernatants of ex-vivo isolated B-cell subsets, could be performed using the novel "glomerulus-on-a-chip" technology (31). This artificial platform mimics the glomerular permeability barrier composed of human podocytes, glomerular endothelial cells and extracellular matrix resembling the glomerular basement membrane (31).

In contrast to antibodies directed against podocytes, B cells could also exert detrimental effects by producing antibodies that can indirectly alter the immune homeostasis of INS patients. In this regard, a recent study reports the production of hyposialylated IgM directed against $\mathrm{T}$ cells, which inversely correlates with the extent of the response to steroid treatment, in a subgroup of SSNS pediatric patients (32). This study demonstrates that sialylated IgM targeting $\mathrm{T}$ cells are rapidly internalized and inhibit $\mathrm{T}$-cell activation in vitro. In contrast, hyposialylated IgM, which can also target $\mathrm{T}$ cells, remain on the 
cell surface after binding but fail to exert inhibitory effects. More importantly, the binding of hyposialylated IgM renders $\mathrm{T}$ cells unresponsive to steroid inhibition and favors the secretion of podocyte damaging factors from activated $\mathrm{T}$ cells (32). These observations suggest that hyposialylated IgM could sustain T-cell activation induced by external triggers such as infections or atopy and could reduce $\mathrm{T}$-cell response to steroid inhibition. Additional studies are needed to define the mechanism responsible of the production of hyposialylated $\operatorname{IgM}$ and to investigate whether immunosuppressive agents other than steroids can revert this phenomenon.

\section{ANTIBODY-INDEPENDENT ROLE OF B CELLS IN INS}

The potential role of T-cell derived cytokines in the pathogenesis of INS has been largely investigated, with contrasting results (6, 33). Among them, an increased production of IL-13 and TNFalpha seems to be the most relevant and reproducible in INS (6, 33). In contrast, the role of B-cell derived cytokines has been poorly investigated. Of note, B cells are able to secrete both IL-13 and TNF-alpha, as well as other potentially pathogenic cytokines such as IL-4, IFN-gamma, IL-6 and IL-17 $(20,34)$. IL-13 and IL4 cytokines are usually related to atopy, a condition that is widely associated with first or recurrent episodes of NS (35). In addition, an increased production of IL-4 from mononuclear cells isolated from MCD patients was associated to an increased expression of the B-cell surface CD23, a marker of B-cell activation, in the same patients (36). In 2003, increased levels of soluble CD23, in parallel with increased levels of soluble CD25 (a marker of T-cell activation), were also observed in SSNS pediatric patients in relapse, suggesting a potential role of B cells in sustaining T-cell stimulation (37). However, contrasting results on the amount of serum IL-4 in SSNS patients were reported during years (33). Of note, more than a circulating production of specific cytokines, a local secretion at glomerular level could also be pathogenically relevant in INS, since glomerular infiltration of T and B cells has been reported, especially in FSGS (38). In accordance with this hypothesis, Kim et colleagues elegantly demonstrated that IL-4secreting B cells activated locally in the glomerulus can induce podocyte effacement and proteinuria in an experimental mouse model (39). The detrimental effects exerted by IL-4 on cultured human podocytes are currently being investigated in order to define its involvement in the pathogenesis of INS (40). Since B cells can secrete several immunoregulatory or pro-inflammatory cytokines, a local production of other B-cell derived cytokines could exert comparable or additional pathogenic effects. A recent report describes how IL- 6 can alter the integrity of the glomerular permeability barrier and can derange actin cytoskeleton of in vitro treated podocytes, which constitutively express IL-6 receptor, suggesting a potential pathogenic role also for this cytokine (41).

In parallel with the production of specific cytokines, activated B cells could also directly contribute to T-cell stimulation by expressing surface activating molecules. SSNS is a heterogeneous disorder and the different forms of the disease are likely to be mediated by a complex interplay between the environment, the glomerular permeability barrier and the immune system (5). Despite the lack of a monogenic cause of the disease, genetic variants predisposing to develop SSNS following environmental triggers are emerging, as recently reviewed (42). Among all the identified SSNS-associated genetic variants, the strongest association was found in the HLA region, as identified by exome array and transethnic genome-wide association studies in large pediatric cohorts (43-46), supporting the role of an immune dysregulation in the antigen presentation machinery in SSNS forms (44). In agreement with this hypothesis, a recent study showed that INS relapses were associated with a decrease in $\mathrm{T}$ regulatory cells and IL-2 expression whereas remission phases under rituximab therapy were associated with a significant decrease in invariant natural killer T cells and CD4CD8- T-cells expressing the invariant V $\alpha 24$ chain T-cells. These observations suggest that $\mathrm{B}$-cell depleting agents may interfere in T cell-B cell cooperation during the course of the disease (47).

Additional studies should be performed to investigate the Bcell specific expression of activated molecules and their direct interaction with $\mathrm{T}$ cells in INS patients.

\section{B-CELL PHENOTYPE IN INS}

In 2004, the casual observation of a sustained NS remission in a boy treated with rituximab for his recurrent idiopathic thrombocytopenic purpura proves for the first time the pathogenic role of B cells in INS (8). The successful use of Bcell depleting anti-CD20 monoclonal antibodies in maintaining long-lasting remission and allowing tapering of concomitant immunosuppressive treatment in both pediatric and adults INS patients has subsequently supported the hypothesis of a key role of B lymphocytes in the pathogenesis of INS $(3,9,10)$. Interestingly, other immunosuppressive drugs frequently used for the treatment of INS, such as mycophenolate mofetil and calcineurin inhibitors, can target $\mathrm{T}$ cells but are also effective in inhibiting B-cell proliferation and immunoglobulin production, and can contribute to maintain remission following anti-CD20 treatment $(5,15,48,49)$. The amount of circulating B cells has been largely investigated in children with INS. Table 1 summarizes the most relevant studies describing the B-cell phenotype in INS patients. High levels of B cells were already described in SSNS pediatric patients in 2002 (50). However, several subsequent studies reported conflicting results (51-53). Some of the observed discrepancies could be related to the immunosuppression received by most of the described patients before sampling, since the number of total B cells is determined by the proportion of different B-cell subsets that have differential sensitivities to immunosuppressive agents such as steroids, mycophenolate mofetil and calcineurin inhibitors (48). Prednisone treatment, for example, can exert long-lasting effects on different B-cell subsets also several months after interruption, as recently reported in children with SSNS (57). To avoid these confounding effects, the entire circulating B-cell 
TABLE 1 | B-cell phenotype in idiopathic nephrotic syndrome patients.

\begin{tabular}{|c|c|c|c|c|c|c|c|c|}
\hline & \multirow[t]{2}{*}{ Type } & \multirow[t]{2}{*}{ Status } & \multirow[t]{2}{*}{ Treatment } & \multicolumn{5}{|c|}{ B-cell subsets } \\
\hline & & & & $\begin{array}{l}\text { Total } \\
\text { CD19 }^{+}\end{array}$ & Transitional & Mature & Memory & Plasmablasts \\
\hline \multicolumn{9}{|l|}{ Children } \\
\hline \multirow[t]{4}{*}{ Lama et al. (50) } & SSNS & Relapse & Off therapy & $\uparrow$ & ND & ND & ND & ND \\
\hline & & Remission & Off therapy & $\uparrow$ & ND & ND & ND & ND \\
\hline & SRNS & Relapse & Off therapy & $\uparrow$ & ND & ND & ND & ND \\
\hline & & Remission & Off therapy & $\uparrow$ & ND & ND & ND & ND \\
\hline \multirow[t]{4}{*}{ Kemper et al. (51) } & SSNS & Relapse & Off therapy & $\downarrow$ & ND & ND & ND & ND \\
\hline & & & On PDN & $\uparrow$ & ND & ND & ND & ND \\
\hline & & Remission & Off therapy & $\downarrow$ & ND & ND & ND & ND \\
\hline & & & On PDN & $\uparrow$ & ND & ND & ND & ND \\
\hline \multirow{2}{*}{$\begin{array}{l}\text { Lapillonne et al. } \\
\text { (52) }\end{array}$} & SSNS & Relapse & Off therapy & $=$ & ND & ND & ND & ND \\
\hline & & Remission & Off therapy & $\downarrow$ & ND & ND & ND & ND \\
\hline \multirow[t]{3}{*}{ Printza et al. (53) } & SSNS & Onset & Untreated & $\uparrow$ & ND & ND & ND & ND \\
\hline & & Remission & On PDN & $=$ & ND & ND & ND & ND \\
\hline & & & After PDN discontinuation & $=$ & ND & ND & ND & ND \\
\hline \multirow[t]{4}{*}{ Colucci et al. (54) } & SSNS & Onset & Untreated & $\uparrow$ & $\uparrow$ & $=$ & $\uparrow$ & ND \\
\hline & & Relapse & $\mathrm{On} \mathrm{PDN} \pm \mathrm{MMF} \pm \mathrm{CNls}$ & $=$ & $=$ & $\downarrow$ & $\uparrow$ & ND \\
\hline & & Remission & On PDN \pm MMF \pm CNIs & $\downarrow$ & $\downarrow$ & $\downarrow$ & $=$ & ND \\
\hline & $\begin{array}{l}\text { Genetic } \\
\text { SRNS }\end{array}$ & - & Untreated or on PDN or CNIs & $=$ & $=$ & $=$ & $=$ & ND \\
\hline \multirow[t]{4}{*}{ Ling et al. (55) } & SSNS & Onset & Untreated & $\uparrow$ & $\uparrow$ & $\downarrow$ & $\uparrow$ & ND \\
\hline & & Relapse & On PDN & $\uparrow$ & $=$ & $\downarrow$ & $\uparrow$ & ND \\
\hline & & Remission & On PDN & $=$ & $=$ & $=$ & $\uparrow$ & ND \\
\hline & SRNS & Onset & Untreated & $=$ & $=$ & $\downarrow$ & $\uparrow$ & ND \\
\hline Ling et al. (56) & SSNS & $\begin{array}{c}\text { Relapsing vs } \\
\text { Non- } \\
\text { relapsing }\end{array}$ & $\begin{array}{c}\text { Untreated (onset) or on PDN (relapse and } \\
\text { remission) }\end{array}$ & $=^{\star}$ & $\downarrow^{*}$ & $=^{\star}$ & $\uparrow^{\star}$ & ND \\
\hline \multirow[t]{3}{*}{ Ling et al. (57) } & SSNS & Onset & Untreated & $\uparrow$ & $\uparrow$ & $=$ & $=$ & ND \\
\hline & & Remission & On PDN & $=$ & $\downarrow$ & $=$ & $\uparrow$ & ND \\
\hline & & & After PDN discontinuation & $\downarrow$ & $\downarrow$ & $=$ & $=$ & ND \\
\hline \multirow[t]{3}{*}{ Zotta et al. (58) } & SSNS & Onset & Untreated & ND & ND & ND & ND & $=$ \\
\hline & & Relapse & $\mathrm{On} \mathrm{PDN} \pm \mathrm{MMF} \pm \mathrm{CNIS}$ & ND & ND & ND & ND & $=$ \\
\hline & & Remission & $\mathrm{On} P \mathrm{PDN} \pm \mathrm{MMF} \pm \mathrm{CNls}$ & ND & ND & ND & ND & $=$ \\
\hline \multicolumn{9}{|l|}{ Adults } \\
\hline \multirow{2}{*}{$\begin{array}{l}\text { Oniszczuk et al. } \\
\text { (59) }\end{array}$} & MCD & Relapse & Off therapy & $=$ & $=$ & $=$ & $=$ & $\uparrow$ \\
\hline & & Remission & Off therapy & $=$ & $=$ & $=$ & $=$ & $=$ \\
\hline
\end{tabular}

SSNS, steroid-sensitive nephrotic syndrome; SRNS, steroid-resistant nephrotic syndrome; MCD, Minimal change disease.

Off therapy, patients without treatment for at least 6 months; untreated, patients at onset of the disease before starting prednisone treatment; PDN, prednisone; MMF, mycophenolate mofetil; CNIs, calcineurin inhibitors.

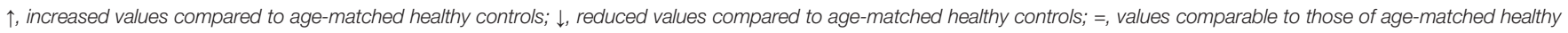
controls; ND, not determined.

*, Values compared between relapsing and non-relapsing patients.

repertoire has been characterized in a large cohort of SSNS pediatric patients at onset of disease before starting any immunosuppressive drug by Colucci et al. $(54,58)$. Increased levels of transitional and memory $\mathrm{B}$ cells, which together contributed to an increased amount of total B cells, were found. However, when SSNS patients treated with prednisone and one or two steroid-sparing agents were analyzed, transitional and mature/naïve B cells were mostly affected by immunosuppression, both in relapse and in remission, whilst memory B cells were found to be less sensitive to treatment (54). Similar results were also obtained by Ling and colleagues, who have recently demonstrated that increased levels of total, transitional and memory B cells can help in discriminating SSNS children from SRNS patients and that a reduced transitional/memory B-cell ratio is significantly predictive of
SSNS recurrence $(55,56)$. Altogether, these results suggest that, among all the B-cell subpopulations, memory B cells play a key role in the pathogenesis of pediatric SSNS. Accordingly, the reappearance of memory B cells is highly effective in predicting relapse following anti-CD20 treatment in SSNS children (60-62).

In contrast to children, data regarding the distribution of circulating B cells in adult patients with INS at disease onset or during B-cell reconstitution after administration of anti-CD20 monoclonal antibodies are scarce. To our knowledge, only one study by Oniszczuk et al. showed that, among all the analyzed circulating B-cell subpopulations, plasmablasts were the only subset present at significantly higher levels during MCD relapses from untreated adult patients in comparison with patients in remission and with healthy controls (59). Of note, plasmablasts were also significantly increased in patients with biopsy-proven 
membranous nephropathy (an antibody-mediated glomerular disease characterized by an intense proteinuria, similar to that observed in MCD patients) (59). In this study, plasmablast levels during relapse were correlated with both lower albumin levels and higher proteinuria levels and were significantly associated to higher IgM levels and decreased IgG levels. In addition, an increased production of IL-21, IL-6 and B-cell activating factor (BAFF) was found in MCD patients with nephrotic-range proteinuria. Interestingly, the expansion of the plasmablast population may be partially explained by an increase of BAFF production, providing new evidence for the therapeutic use of anti-BAFF therapy (59). Of note, evaluation of plasmablast levels in children yielded conflicting results. Yang et al. reported higher levels of circulating plasmablasts in 94 children with new onset untreated INS patients, including both steroid-sensitive and steroid-resistant patients, compared to healthy controls (63). However, this increase in circulating plasmablasts was not confirmed in a subsequent study including only children with SSNS (58).

Altogether, these data suggest that alterations of the B-cell homeostasis observed in pediatric and adult INS patients are quite dissimilar, possibly due to the different maturity of the immune system between adults and children (16). This could also in part explain the distinct timing of response to steroid treatment in pediatric and adult patients with INS $(2,4)$, since prednisone differentially targets each B-cell subset (48).

Additional studies are needed to define the key pathogenic Bcell subset(s) in INS. A French multicenter trial is ongoing to test the efficacy of rituximab to maintain remission of a new-onset MCD episode in 98 adult patients who will either receive two doses of rituximab $\left(375 \mathrm{mg} / \mathrm{m}^{2}\right.$ separated by 1 week) or a progressive tapering of prednisone doses ('RIFIREINS', NCT03970577, Rituximab From the FIRst Episode of Idiopathic Nephrotic Syndrome). The main objective of this study will be to demonstrate that the use of rituximab from the initial episode of MCD in adults may significantly reduce the risk of subsequent relapses and limit prolonged exposure to steroids without serious adverse events. Enrolled patients will be rigorously classified as steroid-sensitive, steroid-dependent or steroid-resistant INS based on their response to a standardized

\section{REFERENCES}

1. Noone DG, Iijima K, Parekh R. Idiopathic Nephrotic Syndrome in Children. Lancet (2018) 392:61-74. doi: 10.1016/S0140-6736(18)30536-1

2. Vivarelli M, Massella L, Ruggiero B, Emma F. Minimal Change Disease. Clin J Am Soc Nephrol (2017) 12:332-45. doi: 10.2215/CJN.05000516

3. Gauckler P, Shin JI, Alberici F, Audard V, Bruchfeld A, Busch M, et al. Rituximab in Adult Minimal Change Disease and Focal Segmental Glomerulosclerosis - What is Known and What Is Still Unknown? Autoimmun Rev (2020) 19:102671. doi: 10.1016/j.autrev.2020.102671

4. Remy P, Audard V, Natella PA, Pelle G, Dussol B, Leray-Moragues H, et al. An Open-Label Randomized Controlled Trial of Low-Dose Corticosteroid Plus Enteric-Coated Mycophenolate Sodium Versus Standard Corticosteroid Treatment for Minimal Change Nephrotic Syndrome in Adults (MSN Study). Kidney Int (2018) 94:1217-26. doi: 10.1016/j.kint.2018.07.021

5. Colucci M, Corpetti G, Emma F, Vivarelli M. Immunology of Idiopathic Nephrotic Syndrome. Pediatr Nephrol (2018) 33:573-84. doi: 10.1007/ s00467-017-3677-5 induction therapy with prednisone. In addition, this prospective trial will include an extensive B and T lymphocyte subpopulation monitoring, in order to investigate the potential close relationship between lymphocyte subpopulations and treatment response at different crucial timepoints and in different forms of the disease. The obtained results will help to improve our understanding of the role of lymphocyte subsets in the pathogenesis of INS in adulthood.

\section{CONCLUSION}

The accurate molecular mechanisms underlying INS pathogenesis remain to be determined, but compelling data suggest that INS results from immune disorders leading to the release of circulating glomerular permeability factors, possibly $\mathrm{T}$ and/or B cell-derived, which in turn alter the glomerular filtration barrier and promote podocyte damages. The recent successful use of anti-CD20 monoclonal antibodies as supportive treatment of some forms of INS in children and adult patients provide additional evidence of a potential key role of $B$ lymphocytes in the pathophysiological processes involved in this quite mysterious glomerular disease. Further studies are needed to elucidate the precise mechanisms by which and which B lymphocytes subpopulation could target the glomerular filtration barrier.

\section{AUTHOR CONTRIBUTIONS}

Conception and design: MC, JO, MV, and VA. Analysis of the data and preparation of the figure: $\mathrm{MC}$ and JO. Drafting and revision of the manuscript: $\mathrm{MC}, \mathrm{JO}, \mathrm{MV}$, and VA. All authors contributed to the article and approved the submitted version.

\section{ACKNOWLEDGMENTS}

$\mathrm{MC}$ and $\mathrm{MV}$ are supported by Fondazione Bambino Gesù Onlus and Ricerca Corrente of the Italian Ministry of Health.

6. Davin JC. The Glomerular Permeability Factors in Idiopathic Nephrotic Syndrome. Pediatr Nephrol (2016) 31:207-15. doi: 10.1007/s00467-0153082-x

7. Shalhoub RJ. Pathogenesis of Lipoid Nephrosis: A Disorder of T-Cell Function. Lancet (1974) 2:556-60. doi: 10.1016/s0140-6736(74)91880-7

8. Benz K, Dotsch J, Rascher W, Stachel D. Change of the Course of SteroidDependent Nephrotic Syndrome After Rituximab Therapy. Pediatr Nephrol (2004) 19:794-7. doi: 10.1007/s00467-004-1434-z

9. Iijima K, Sako M, Nozu K, Mori R, Tuchida N, Kamei K, et al. Rituximab for Childhood-Onset, Complicated, Frequently Relapsing Nephrotic Syndrome or Steroid-Dependent Nephrotic Syndrome: A Multicentre, Double-Blind, Randomised, Placebo-Controlled Trial. Lancet (2014) 384:1273-81. doi: 10.1016/S0140-6736(14)60541-9

10. Ravani P, Bonanni A, Rossi R, Caridi G, Ghiggeri GM. Anti-CD20 Antibodies for Idiopathic Nephrotic Syndrome in Children. Clin J Am Soc Nephrol (2016) 11:710-20. doi: 10.2215/CJN.08500815

11. Ravani P, Colucci M, Bruschi M, Vivarelli M, Cioni M, DiDonato A, et al. Human or Chimeric Monoclonal Anti-CD20 Antibodies for Children With 
Nephrotic Syndrome: A Superiority Randomized Trial. J Am Soc Nephrol (2021) 32:2652-63. doi: 10.1681/ASN.2021040561

12. Audard V, Larousserie F, Grimbert P, Abtahi M, Sotto JJ, Delmer A, et al. Minimal Change Nephrotic Syndrome and Classical Hodgkin's Lymphoma: Report of 21 Cases and Review of the Literature. Kidney Int (2006) 69:225160. doi: 10.1038/sj.ki.5000341

13. Audard V, Zhang SY, Copie-Bergman C, Rucker-Martin C, Ory V, Candelier $\mathrm{M}$, et al. Occurrence of Minimal Change Nephrotic Syndrome in Classical Hodgkin Lymphoma is Closely Related to the Induction of C-Mip in Hodgkin-Reed Sternberg Cells and Podocytes. Blood (2010) 115:3756-62. doi: 10.1182/blood-2009-11-251132

14. Kofman T, Zhang SY, Copie-Bergman C, Moktefi A, Raimbourg Q, Francois $\mathrm{H}$, et al. Minimal Change Nephrotic Syndrome Associated With nonHodgkin Lymphoid Disorders: A Retrospective Study of 18 Cases. Med (Baltimore) (2014) 93:350-8. doi: 10.1097/MD.0000000000000206

15. Dossier C, Jamin A, Deschenes G. Idiopathic Nephrotic Syndrome: The EBV Hypothesis. Pediatr Res (2017) 81:233-9. doi: 10.1038/pr.2016.200

16. Blanco E, Perez-Andres M, Arriba-Mendez S, Contreras-Sanfeliciano T, Criado I, Pelak O, et al. Age-Associated Distribution of Normal B-Cell and Plasma Cell Subsets in Peripheral Blood. J Allergy Clin Immunol (2018) 141:2208-19.e16. doi: 10.1016/j.jaci.2018.02.017

17. Cyster JG, Allen CDC. B Cell Responses: Cell Interaction Dynamics and Decisions. Cell (2019) 177:524-40. doi: 10.1016/j.cell.2019.03.016

18. Hoffman W, Lakkis FG, Chalasani GB. Cells, Antibodies, and More. Clin J Am Soc Nephrol (2016) 11:137-54. doi: 10.2215/CJN.09430915

19. Oleinika K, Mauri C, Salama AD. Effector and Regulatory B Cells in ImmuneMediated Kidney Disease. Nat Rev Nephrol (2019) 15:11-26. doi: 10.1038/ s41581-018-0074-7

20. Shen P, Fillatreau S. Antibody-Independent Functions of B Cells: A Focus on Cytokines. Nat Rev Immunol (2015) 15:441-51. doi: 10.1038/nri3857

21. Morbach H, Wiegering V, Richl P, Schwarz T, Suffa N, Eichhorn EM, et al. Activated Memory B Cells may Function as Antigen-Presenting Cells in the Joints of Children With Juvenile Idiopathic Arthritis. Arthritis Rheumatol (2011) 63:3458-66. doi: 10.1002/art.30569

22. Maas RJ, Deegens JK, Smeets B, Moeller MJ, Wetzels JF. Minimal Change Disease and Idiopathic FSGS: Manifestations of the Same Disease. Nat Rev Nephrol (2016) 12:768-76. doi: 10.1038/nrneph.2016.147

23. Strassheim D, Renner B, Panzer S, Fuquay R, Kulik L, Ljubanovic D, et al. IgM Contributes to Glomerular Injury in FSGS. J Am Soc Nephrol (2013) 24:393406. doi: 10.1681/ASN.2012020187

24. Pacic A, Senjug P, Bacalja J, Tisljar M, Horvatic I, Bulimbasic S, et al. IgM as a Novel Predictor of Disease Progression in Secondary Focal Segmental Glomerulosclerosis. Croat Med J (2017) 58:281-91. doi: 10.3325/cmj. 2017.58.281

25. Dantal J, Godfrin Y, Koll R, Perretto S, Naulet J, Bouhours JF, et al. Antihuman Immunoglobulin Affinity Immunoadsorption Strongly Decreases Proteinuria in Patients With Relapsing Nephrotic Syndrome. J Am Soc Nephrol (1998) 9:1709-15. doi: 10.1681/ASN.V991709

26. Giangiacomo J, Cleary TG, Cole BR, Hoffsten P, Robson AM. Serum Immunoglobulins in the Nephrotic Syndrome. A Possible Cause of Minimal-Change Nephrotic Syndrome. N Engl J Med (1975) 293:8-12. doi: 10.1056/NEJM197507032930103

27. Beale MG, Hoffsten PE, Robson AM, MacDermott RP. Inhibitory Factors of Lymphocyte Transformation in Sera From Patients With Minimal Change Nephrotic Syndrome. Clin Nephrol (1980) 13:271-6.

28. Delville M, Sigdel TK, Wei C, Li J, Hsieh SC, Fornoni A, et al. A Circulating Antibody Panel for Pretransplant Prediction of FSGS Recurrence After Kidney Transplantation. Sci Transl Med (2014) 6:256ra136. doi: 10.1126/ scitranslmed.3008538

29. Jamin A, Berthelot L, Couderc A, Chemouny JM, Boedec E, Dehoux L, et al. Autoantibodies Against Podocytic UCHL1 Are Associated With Idiopathic Nephrotic Syndrome Relapses and Induce Proteinuria in Mice. J Autoimmun (2018) 89:149-61. doi: 10.1016/j.jaut.2017.12.014

30. Watts A, Keller K, Lerner G, Rosales I, Collins A, Sekulic M, et al. Discovery of Autoantibodies Targeting Nephrin in Minimal Change Disease Supports a Novel Autoimmune Etiology. J Am Soc Nephrol (2022) 33:238-52. doi: 10.1681/ ASN.2021060794
31. Petrosyan A, Cravedi P, Villani V, Angeletti A, Manrique J, Renieri A, et al. A Glomerulus-on-a-Chip to Recapitulate the Human Glomerular Filtration Barrier. Nat Commun (2019) 10(1):3656. doi: 10.1038/s41467-019-11577-z

32. Colucci M, Carsetti R, Rosado MM, Cascioli S, Bruschi M, Candiano G, et al. Atypical IgM on T Cells Predict Relapse and Steroid Dependence in Idiopathic Nephrotic Syndrome. Kidney Int (2019) 96:971-82. doi: 10.1016/ j.kint.2019.04.006

33. Araya CE, Wasserfall CH, Brusko TM, Mu W, Segal MS, Johnson RJ, et al. A Case of Unfulfilled Expectations. Cytokines in Idiopathic Minimal Lesion Nephrotic Syndrome. Pediatr Nephrol (2006) 21:603-10. doi: 10.1007/s00467006-0026-5

34. Johansson-Lindbom B, Borrebaeck CA. Germinal Center B Cells Constitute a Predominant Physiological Source of IL-4: Implication for Th2 Development In Vivo. J Immunol (2002) 168:3165-72. doi: 10.4049/jimmunol.168.7.3165

35. Abdel-Hafez M, Shimada M, Lee PY, Johnson RJ, Garin EH. Idiopathic Nephrotic Syndrome and Atopy: Is There a Common Link? Am J Kidney Dis (2009) 54:945-53. doi: 10.1053/j.ajkd.2009.03.019

36. Cho BS, Yoon SR, Jang JY, Pyun KH, Lee CE. Up-Regulation of Interleukin-4 and CD23/FcepsilonRII in Minimal Change Nephrotic Syndrome. Pediatr Nephrol (1999) 13:199-204. doi: 10.1007/s004670050592

37. Kemper MJ, Meyer-Jark T, Lilova M, Muller-Wiefel DE. Combined T- and BCell Activation in Childhood Steroid-Sensitive Nephrotic Syndrome. Clin Nephrol (2003) 60:242-7. doi: 10.5414/cnp60242

38. Benz K, Buttner M, Dittrich K, Campean V, Dotsch J, Amann K. Characterisation of Renal Immune Cell Infiltrates in Children With Nephrotic Syndrome. Pediatr Nephrol (2010) 25:1291-8. doi: 10.1007/ s00467-010-1507-0

39. Kim AH, Chung JJ, Akilesh S, Koziell A, Jain S, Hodgin JB, et al. B CellDerived IL-4 Acts on Podocytes to Induce Proteinuria and Foot Process Effacement. JCI Insight (2017) 2:e81836. doi: 10.1172/jci.insight.81836

40. Lee JM, Ko Y, Lee CH, Jeon N, Lee KH, Oh J, et al. The Effect of Interleukin-4 and Dexamethasone on RNA-Seq-Based Transcriptomic Profiling of Human Podocytes: A Potential Role in Minimal Change Nephrotic Syndrome. J Clin Med (2021) 10:496 doi: 10.3390/jcm10030496

41. Srivastava T, Joshi T, Heruth DP, Rezaiekhaligh MH, Garola RE, Zhou J, et al. A Mouse Model of Prenatal Exposure to Interleukin-6 to Study the Developmental Origin of Health and Disease. Sci Rep (2021) 11:13260. doi: 10.1038/s41598-021-92751-6

42. Dufek-Kamperis S, Kleta R, Bockenhauer D, Gale D, Downie ML. Novel Insights in the Genetics of Steroid-Sensitive Nephrotic Syndrome in Childhood. Pediatr Nephrol (2021) 36(8):2165-75. doi: 10.1007/s00467-02004780-4

43. Gbadegesin RA, Adeyemo A, Webb NJ, Greenbaum LA, Abeyagunawardena A, Thalgahagoda S, et al. HLA-DQA1 and PLCG2 Are Candidate Risk Loci for Childhood-Onset Steroid-Sensitive Nephrotic Syndrome. J Am Soc Nephrol (2015) 26:1701-10. doi: 10.1681/ASN.2014030247

44. Debiec H, Dossier C, Letouze E, Gillies CE, Vivarelli M, Putler RK, et al. Transethnic, Genome-Wide Analysis Reveals Immune-Related Risk Alleles and Phenotypic Correlates in Pediatric Steroid-Sensitive Nephrotic Syndrome. J Am Soc Nephrol (2018) 29:2000-13. doi: 10.1681/ ASN.2017111185

45. Dufek S, Cheshire C, Levine AP, Trompeter RS, Issler N, Stubbs M, et al. Genetic Identification of Two Novel Loci Associated With Steroid-Sensitive Nephrotic Syndrome. J Am Soc Nephrol (2019) 30(8):1375-84. doi: 10.1681/ ASN.2018101054

46. Jia X, Yamamura T, Gbadegesin R, McNulty MT, Song K, Nagano C, et al. Common Risk Variants in NPHS1 and TNFSF15 Are Associated With Childhood Steroid-Sensitive Nephrotic Syndrome. Kidney Int (2020) 98 (5):1308-22. doi: 10.1016/j.kint.2020.05.029

47. Boumediene A, Vachin P, Sendeyo K, Oniszczuk J, Zhang SY, Henique C, et al. NEPHRUTIX: A Randomized, Double-Blind, Placebo vs RituximabControlled Trial Assessing T-Cell Subset Changes in Minimal Change Nephrotic Syndrome. J Autoimmun (2018) 88:91-102. doi: 10.1016/ j.jaut.2017.10.006

48. Schrezenmeier E, Jayne D, Dorner T. Targeting B Cells and Plasma Cells in Glomerular Diseases: Translational Perspectives. J Am Soc Nephrol (2018) 29:741-58. doi: 10.1681/ASN.2017040367 
49. Chan EY, Webb H, Yu E, Ghiggeri GM, Kemper MJ, Ma AL, et al. Both the Rituximab Dose and Maintenance Immunosuppression in SteroidDependent/Frequently-Relapsing Nephrotic Syndrome Have Important Effects on Outcomes. Kidney Int (2020) 97:393-401. doi: 10.1016/ j.kint.2019.09.033

50. Lama G, Luongo I, Tirino G, Borriello A, Carangio C, Salsano ME. TLymphocyte Populations and Cytokines in Childhood Nephrotic Syndrome. Am J Kidney Dis (2002) 39:958-65. doi: 10.1053/ajkd.2002.32769

51. Kemper MJ, Zepf K, Klaassen I, Link A, Muller-Wiefel DE. Changes of Lymphocyte Populations in Pediatric Steroid-Sensitive Nephrotic Syndrome are More Pronounced in Remission Than in Relapse. Am J Nephrol (2005) 25:132-7. doi: 10.1159/000085357

52. Lapillonne H, Leclerc A, Ulinski T, Balu L, Garnier A, Dereuddre-Bosquet N, et al. Stem Cell Mobilization in Idiopathic Steroid-Sensitive Nephrotic Syndrome. Pediatr Nephrol (2008) 23:1251-6. doi: 10.1007/s00467-008-0793-2

53. Printza N, Papachristou F, Tzimouli V, Taparkou A, Kanakoudi-Tsakalidou F. Peripheral CD19+ B Cells are Increased in Children With Active SteroidSensitive Nephrotic Syndrome. NDT Plus (2009) 2:435-6. doi: 10.1093/ ndtplus/sfp087

54. Colucci M, Carsetti R, Cascioli S, Serafinelli J, Emma F, Vivarelli M. B Cell Phenotype in Pediatric Idiopathic Nephrotic Syndrome. Pediatr Nephrol (2019) 34:177-81. doi: 10.1007/s00467-018-4095-Z

55. Ling C, Wang X, Chen Z, Fan J, Meng Q, Zhou N, et al. Altered B-Lymphocyte Homeostasis in Idiopathic Nephrotic Syndrome. Front Pediatr (2019) 7:377. doi: 10.3389/fped.2019.00377

56. Ling C, Chen Z, Fan J, Sun Q, Wang X, Hua L, et al. Decreased Circulating Transitional B-Cell to Memory B-Cell Ratio Is a Risk Factor for Relapse in Children With Steroid-Sensitive Nephrotic Syndrome. Nephron (2021) 145:107-12. doi: 10.1159/000511319

57. Ling C, Chen Z, Wang X, Hua L, Gui J, Liu X. B Lymphocyte Subsets in Children With Steroid-Sensitive Nephrotic Syndrome: A Longitudinal Study. Front Pediatr (2021) 9:736341. doi: 10.3389/fped.2021.736341

58. Zotta F, Vivarelli M, Carsetti R, Cascioli S, Emma F, Colucci M. Circulating Plasmablasts in Children With Steroid-Sensitive Nephrotic Syndrome. Pediatr Nephrol (2021). doi: 10.1007/s00467-021-05273-8

59. Oniszczuk J, Beldi-Ferchiou A, Audureau E, Azzaoui I, Molinier-Frenkel V, Frontera V, et al. Circulating Plasmablasts and High Level of BAFF Are
Hallmarks of Minimal Change Nephrotic Syndrome in Adults. Nephrol Dial Transplant (2021) 36:609-17. doi: 10.1093/ndt/gfaa279

60. Colucci M, Carsetti R, Cascioli S, Casiraghi F, Perna A, Rava L, et al. B Cell Reconstitution After Rituximab Treatment in Idiopathic Nephrotic Syndrome. J Am Soc Nephrol (2016) 27:1811-22. doi: 10.1681/ASN. 2015050523

61. Bhatia D, Sinha A, Hari P, Sopory S, Saini S, Puraswani M, et al. Rituximab Modulates T- and B-Lymphocyte Subsets and Urinary CD80 Excretion in Patients With Steroid-Dependent Nephrotic Syndrome. Pediatr Res (2018) 84:520-6. doi: 10.1038/s41390-018-0088-7

62. Fribourg M, Cioni M, Ghiggeri G, Cantarelli C, Leventhal JS, Budge K, et al. CyTOF-Enabled Analysis Identifies Class-Switched B Cells as the Main Lymphocyte Subset Associated With Disease Relapse in Children With Idiopathic Nephrotic Syndrome. Front Immunol (2021) 12:726428. doi: 10.3389/fimmu.2021.726428

63. Yang X, Tang X, Li T, Man C, Yang X, Wang M, et al. Circulating Follicular T Helper Cells Are Possibly Associated With Low Levels of Serum Immunoglobulin G Due to Impaired Immunoglobulin Class-Switch Recombination of B Cells in Children With Primary Nephrotic Syndrome. Mol Immunol (2019) 114:162-70. doi: 10.1016/j.molimm.2019.07.001

Conflict of Interest: The authors declare that the research was conducted in the absence of any commercial or financial relationships that could be construed as a potential conflict of interest.

Publisher's Note: All claims expressed in this article are solely those of the authors and do not necessarily represent those of their affiliated organizations, or those of the publisher, the editors and the reviewers. Any product that may be evaluated in this article, or claim that may be made by its manufacturer, is not guaranteed or endorsed by the publisher.

Copyright (C) 2022 Colucci, Oniszczuk, Vivarelli and Audard. This is an open-access article distributed under the terms of the Creative Commons Attribution License (CC BY). The use, distribution or reproduction in other forums is permitted, provided the original author(s) and the copyright owner(s) are credited and that the original publication in this journal is cited, in accordance with accepted academic practice. No use, distribution or reproduction is permitted which does not comply with these terms. 